\title{
Relationship between pain relief, reduction in pain-associated sleep interference, and overall impression of improvement in patients with postherpetic neuralgia treated with extended-release gabapentin
}

\author{
Neel Mehta ${ }^{*}$, Iwona Bucior², Shay Bujanover ${ }^{2}$, Rajiv Shah ${ }^{3}$ and Amitabh Gulati ${ }^{4}$
}

\begin{abstract}
Background: Postherpetic neuralgia (PHN) interferes with patients' quality of life, and disturbed sleep is a prevalent complaint. Pain-associated sleep interference in turn enhances pain and/or reduces pain tolerance. Therefore, reducing sleep interference by pain, in addition to pain control, may improve patient care. To address this notion, we characterized relationships among changes in pain intensity, sleep interference, and overall impression of improvement in PHN patients treated with gastroretentive gabapentin (G-GR).
\end{abstract}

Methods: Patients with PHN ( $n=556)$ received G-GR $1800 \mathrm{mg}$ once-daily in two phase 3 and one phase 4 study. Visual Analog Scale (VAS) and Brief Pain Inventory (BPI) were completed at baseline and the end of study. Patients' Global Impression of Change (PGIC) was completed at the end of study. Regression analyses examined relationships between VAS, BPI sleep interference by pain, and PGIC.

Results: At the end of treatment, 53.7 and $63.2 \%$ of patients reported a $\geq 30 \%$ reduction in VAS and BPI pain-associated sleep interference (BPISI) respectively; 46.3 \% reported feeling "Much" or "Very Much" improved on the PGIC. There were positive correlations between the percent reductions in VAS and BPISI; both correlated with PGIC improvements. Percent changes in VAS and BPISI were significant ( $p<0.0001$ and $p=0.0082$, respectively), and were independent predictors of feeling "Much" or "Very Much" improved on the PGIC.

Conclusions: Reductions in pain intensity and in BPISI were correlated, and both also correlated with overall impression of improvement for patients with PHN treated with G-GR. Both pain relief and improvement BPISI independently predicted improvement in PGIC. For optimal patient care, clinicians should consider reducing the impact of pain on quality of sleep as well as overall pain reduction.

Trial registration: ClinicalTrials.gov numbers, NCT00335933, NCT00636636, NCT01426230.

Keywords: Neuropathic pain, Sleep, Quality of life, Postherpetic neuralgia, Gabapentin, Gastroretentive

\footnotetext{
* Correspondence: nem9015@med.cornell.edu

${ }^{1}$ Weill Cornell Medical College of Cornell University, New York, NY, USA

Full list of author information is available at the end of the article
} 


\section{Background}

Postherpetic neuralgia (PHN) is a chronic neuropathic pain syndrome resulting from nerve damage caused by the varicella zoster virus that is reactivated during acute herpes zoster (HZ, shingles) [1]. PHN, which occurs in up to $20 \%$ of $\mathrm{HZ}$ patients, can be debilitating and interferes with patients' physical function and their quality of life [2-6]. Consistent with the tendency of neuropathic pain to be worst during the night [7], sleep disturbance is one of the most common complaints among patients with PHN. Sleep disturbance may in turn lead to additional comorbid conditions such as anxiety or depression [5, 8-10], and some studies suggest that shortened or disturbed sleep may lead to reduced pain tolerance $[11,12]$. Evidence supports a reciprocal relationship between pain and sleep in which pain disturbs sleep, and poor sleep enhances pain $[6,8,13]$. Thus, it is expected that improvement in sleep quality, in addition to control of neuropathic pain, may improve patients' overall quality of life [14].

Although the beneficial effect of various formulations of gabapentin [G-GR [15, 16], gabapentin enacarbil [17], and an immediate-release gabapentin $[18,19]$ on the quality of sleep has been described in several studies, the relationship between changes in pain and sleep and how they contribute to overall patient improvement is complex, and are not well understood. A recent analysis of integrated data from phase 3 and 4 studies of gastroretentive gabapentin (G-GR) $1800 \mathrm{mg}$ once-daily reported widespread, networked, positive correlations among efficacy endpoints, including among pain qualities on the VAS and BPI, pain interference on the BPI, and overall improvement on the PGIC [20]. In the current study, we extend these findings by examining, at the individual patient level, the relationship between changes in pain intensity and pain interference with sleep, and how changes in these measures contribute to patient's overall impression of improvement.

\section{Methods}

\section{Patients}

Individual patient data from $566 \mathrm{PHN}$ patients in two double-blind, randomized, placebo-controlled phase 3 studies (NCT00335933 and NCT 00636636) and one open-label, single-arm phase 4 study (NCT01426230) were pooled in the analysis. Patient inclusion and exclusion criteria of individual studies included in this analysis have been described in detail elsewhere [21-23]. Briefly, in the phase 3 studies, eligible patients were $\geq 18$ years, with neuropathic pain for $\geq 3$ months or $\geq 6$ months after the healing of herpes zoster skin rash, and had an average daily pain score of $\geq 4$ based on an 11-point Likert scale (where $0=$ no pain and $10=$ worst possible pain). In the phase 4 study, patients were relatively unselected to best reflect the real-world population, and included patients $\geq 18$ years with active $\mathrm{PHN}$, regardless of their baseline pain scores. Only patients with valid baseline efficacy measures and who received treatment with GGR $1800 \mathrm{mg}$ once daily were included. Individual study protocols were approved by appropriate institutional review boards/ethics committees for each center and were conducted in accordance with International Conference on Harmonization (ICH) Good Clinical Practice guidelines. Written informed consent was obtained from each patient prior to enrollment.

\section{Treatments}

All three studies shared a similar G-GR treatment schedule: a 2-week titration period, a stable dose treatment period ( 8 weeks for phase 3 , and 6 weeks for phase 4 ), and a 1 -week dose tapering period. The 2 -week titration period used a set schedule: Day 1: $300 \mathrm{mg}$; Day 2: 600 mg; Days 3-6: 900 mg; Days 7-10: 1200 mg; Days 11-14: $1500 \mathrm{mg}$; Day 15: $1800 \mathrm{mg}$.

\section{Efficacy evaluations}

In the current analysis, pain intensity scores were from the 100-mm VAS, which was used in all three studies. For the phase 3 studies, VAS was a component of the ShortForm-McGill Pain Questionnaire (SF-MPQ), completed as a secondary efficacy variable. In the phase 4 study, VAS was the primary efficacy variable for measurement of pain intensity. Pain interference with sleep was evaluated using the BPI, which was one of the secondary efficacy endpoints in both the phase 3 and phase4 studies. Painassociated BPI sleep interference (BPISI) was assessed on an 11-point numeric rating scale (NRS) ranging from 0 (pain does not interfere with sleep) to 10 (pain completely interferes with sleep). Overall improvements on the PGIC were evaluated as secondary efficacy endpoints in phase 3 and phase 4 studies. The VAS and BPI were completed at the end of the baseline week, at Week 2, and at the end of the efficacy treatment period (Week 8 or 10) or early termination. The PGIC was completed at the end of the efficacy treatment period (Week 8 or 10) or early termination. For the integrated analysis, the end of the study was defined as Week 10 for phase 3, and Week 8 for phase 4 .

\section{Statistical methods}

Efficacy analyses were performed for all patients who received $\geq 1$ dose of study drug. Percent changes from baseline to the end of the study in VAS pain intensity and BPISI, and the proportion of patients categorized as "Very Much Improved", "Much Improved", "Minimally Improved", "No Change", "Minimally Worse", "Much Worse", or "Very Much Worse" on the PGIC at the end of the study were determined. Changes from baseline in VAS and BPISI scores were estimated with an analysis of 
covariance (ANCOVA) model that included treatment, study centers, and the baseline value as covariates. As last observation carried forward (LOCF) was the predetermined method approved for all individual studies, missing data were imputed by LOCF to follow approved protocols. Exploratory analyses were designed to examine relationships among treatment outcomes for patients with potentially clinically significant responses to treatment with G-GR. Therefore, "Very Much Improved" and "Much Improved" responses on the PGIC were grouped together, and "Minimally Improved", "No Change", "Minimally Worse", "Much Worse", or "Very Much Worse" were grouped into "Not Improved". Furthermore, in accordance with the published literature and the consensus summary statement produced by the Initiative on Methods,

Table 1 Patient demographics and baseline disease characteristics, safety population

\begin{tabular}{|c|c|}
\hline & $\begin{array}{l}\text { G-GR } 1800 \mathrm{mg} / \text { day } \\
(n=556)\end{array}$ \\
\hline \multicolumn{2}{|l|}{ Age (years) } \\
\hline Mean (SD) & $66.7(12.9)$ \\
\hline Median & 69.0 \\
\hline Range & $18-92$ \\
\hline \multicolumn{2}{|l|}{ Age category, n (\%) } \\
\hline$<55$ years & $89(16.0)$ \\
\hline $55-64$ years & $109(19.6)$ \\
\hline $65-74$ years & $195(35.1)$ \\
\hline$\geq 75$ years & $163(29.3)$ \\
\hline \multicolumn{2}{|l|}{ Sex, n (\%) } \\
\hline Male & $221(39.7)$ \\
\hline Female & $335(60.3)$ \\
\hline \multicolumn{2}{|l|}{ Race, n (\%) } \\
\hline Caucasian & $479(86.2)$ \\
\hline African American & $29(5.2)$ \\
\hline Hispanic & $38(6.8)$ \\
\hline Other & $10(1.8)$ \\
\hline \multicolumn{2}{|l|}{ Baseline VAS (mm) } \\
\hline Mean (SD) & $66.1(56.9)$ \\
\hline Median & 64.0 \\
\hline Range & $2-91$ \\
\hline \multicolumn{2}{|c|}{ Baseline VAS category, n (\%) } \\
\hline$\leq 20 \mathrm{~mm}$ & $15(2.7)$ \\
\hline$>20 \mathrm{~mm}$ & $531(95.5)$ \\
\hline \multicolumn{2}{|c|}{ Baseline BPI Sleep Interference by Pain } \\
\hline Mean (SD) & $5.1(2.9)$ \\
\hline Median & 5 \\
\hline Range & $0-10$ \\
\hline
\end{tabular}

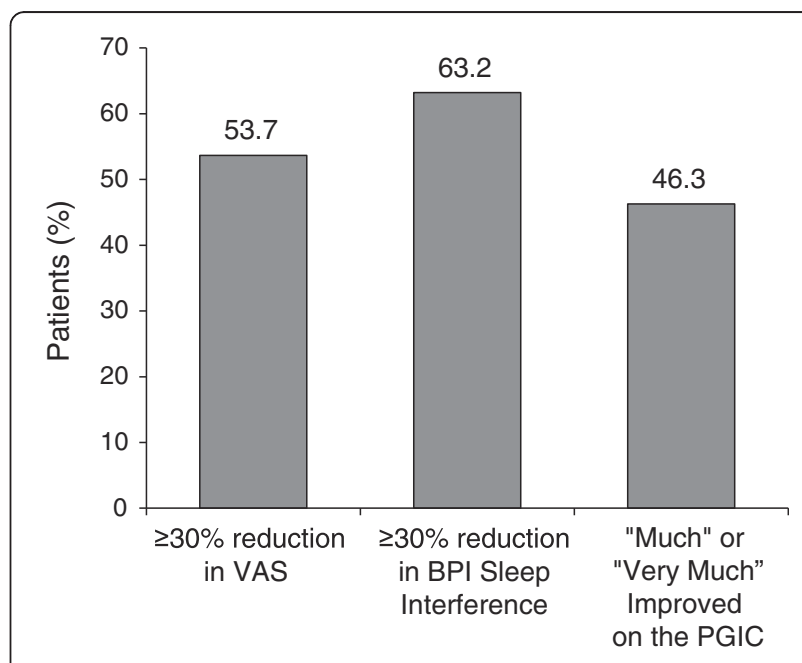

Fig. 1 Proportion of patients who reported $\geq 30 \%$ reductions in the VAS or BPI Sleep Interference by Pain scores, or who reported feeling "Much" or "Very Much" improved at the end of G-GR treatment

Measurement, and Pain Assessment in Clinical Trials (IMMPACT) [24-26], reductions of $\geq 30 \%$ served as determinants of clinically important reductions from baseline in the VAS or BPISI scores. Relationships between percent changes in various efficacy outcomes were examined using linear regression model ANOVA. Multivariable logistic regression analyses were performed to evaluate percent changes in VAS and BPISI as predictive factors for being "Much" or "Very Much" improved on the PGIC. To measure the degree of linear dependence between percent reductions in the VAS and BPISI scores, the Pearson correlation coefficient $(\mathrm{r}$ ) was determined.

\section{Results}

\section{Patient characteristics}

The integrated dataset from the phase 3 and 4 studies included 546 patients in the efficacy population and 556

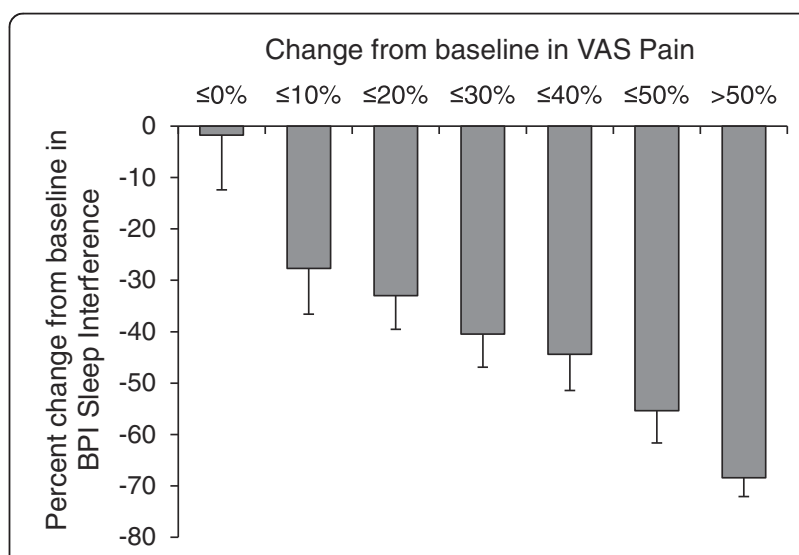

Fig. 2 Percent reduction from baseline in the BPISI score by categories of percent reduction from baseline in the VAS score 
Table 2 Linear Pearson correlation coefficient correlation between VAS and BPI sleep interference by pain

\begin{tabular}{llcl}
\hline & $n$ & $\begin{array}{c}\text { Pearson correlation } \\
\text { coefficient }(r)\end{array}$ & $p$-value \\
\hline $330 \%$ reduction in VAS & 267 & 0.2795 & $<0.0001$ \\
$<30 \%$ reduction in VAS & 225 & 0.0612 & 0.3608 \\
\hline
\end{tabular}

patients in the safety population. Patient demographics and baseline disease characteristics were similar between studies (Table 1). The mean patient age was 66.7 years, and the majority of patients were Caucasian (86.2\%) and female $(60.3 \%)$. The mean baseline VAS score was $66.1 \mathrm{~mm}$ on the $100-\mathrm{mm}$ scale. The mean baseline BPISI score was 5.1 on the $0-10$ NRS scale, and $9 \%$ of patients had a baseline score of 0 .

\section{Correlation between pain relief and sleep interference by pain improvement}

At the end of G-GR treatment, $53.7 \%$ of patients in the efficacy population reported $\geq 30 \%$ reduction in pain intensity on the VAS, $63.2 \%$ of patients reported $\geq 30 \%$ reduction in BPISI, and $46.3 \%$ of patients reported feeling "Much" or "Very Much" improved on the PGIC (Fig. 1). A comparison of changes in VAS and BPISI scores from baseline showed that a larger percent reduction from baseline in the VAS score was associated with a larger percent reduction in the BPISI score at the end of the study (Fig. 2). For patients with clinically significant reduction (defined as $\geq 30 \%$ reduction from baseline) in the VAS score, there was a linear correlation between percent reductions in the VAS and BPISI scores, $(r=0.28, p<0.0001)$, whereas for patients with $<30 \%$ reduction in the VAS score, there was no linear correlation with BPISI $(r=0.0612, p=$ 0.3608 ; Table 2). Significantly more patients with $\geq 30 \%$ reduction in the VAS score from baseline than with $<30 \%$ reduction in the VAS score $(72.0$ vs. $39.5 \%$ of patients, $p<0.0001)$ simultaneously reported $\geq 30 \%$ reduction in the BPISI score (Table 3). Also, among patients with $\geq 30 \%$ reduction in the VAS score from baseline, more simultaneously reported $\geq 30 \%$ reduction in the BPISI score than $<30 \%$ reductions in BPISI score (72.0 vs. $19.1 \%$ of patients, $p<0.0001)$.

\section{Influence of pain relief and sleep improvement on overall impression of improvement}

Better overall improvement as assessed by the PGIC was associated with larger percent reductions from baseline in the VAS (Fig. 3a) and BPISI (Fig. 3b) scores. Significantly more patients with $\geq 30 \%$ reduction than with $<30 \%$ reduction in the VAS score (70.2 vs. $17.9 \%$ of patients, $p<0.0001)$ were "Much" or "Very Much" improved on the PGIC (Table 4). Furthermore, among patients with $\geq 30$ \% reduction in the VAS score, more were "Much" or "Very Much" improved on the PGIC than not improved (70.2 vs. $29.8 \%$ of patients, $p<0.0001)$. In contrast, among patients with $<30 \%$ reduction in the VAS score, more were not improved than "Much" or "Very Much" improved on the PGIC (82.1 vs. $17.9 \%$ of patients, $p<0.0001)$. The relationship between percent reduction in the BPISI score and improvements on the PGIC was similar, and more patients with $\geq 30 \%$ reduction than with $<30 \%$ reduction in the BPISI score (57.8 vs. $26.9 \%$ of patients, $p<0.0001)$ were simultaneously "Much" or "Very Much" improved on the PGIC (Table 5).

Additional exploratory analyses were done to evaluate the influence of percent changes in the VAS and BPI Interference scores on being "Much" or "Very Much" improved on the PGIC. The probability of being "Much" or "Very Much" improved on the PGIC increased with greater percent reductions from baseline in the VAS (Fig. 4a) and BPISI (Fig. 4b) scores, whereas baseline values did not have a positive effect (Figs. 4c, d). Overall, percent changes in the VAS score had a greater influence on the probability of being "Much" or "Very Much" improved on the PGIC than did percent changes in the BPISI score $(p<0.0001$ vs. $p=0.0063)$. Baseline VAS values had a marginally significant $(p=0.0429)$ negative effect, and baseline BPISI values did not have a significant influence $(p=0.8458)$. Furthermore, percent changes from baseline in VAS and BPISI scores were

Table 3 Relationship between percent reduction from baseline in BPI sleep interference by pain and percent reduction in VAS

\begin{tabular}{|c|c|c|c|c|}
\hline & $\geq 30 \%$ reduction in $V^{2} S^{a}$ & $<30 \%$ reduction in $\mathrm{VAS}^{\mathrm{a}}$ & Difference & $\overline{p \text {-value }}$ \\
\hline & $(n=293)$ & $(n=253)$ & $\%(95 \% \mathrm{Cl})$ & \\
\hline$\geq 30 \%$ reduction in BPI Sleep Interference, $n(\%)$ & $211(72.0)$ & $100(39.5)$ & $32.49(24.57,40.41)$ & $<0.0001$ \\
\hline$<30 \%$ reduction in BPI Sleep Interference, $n(\%)$ & $56(19.1)$ & $125(49.4)$ & $-30.29(-37.93,-22.66)$ & $<0.0001$ \\
\hline Difference, \% (95 \% Cl) & $52.90(46.07,59.73)$ & $-9.88(-18.50,-1.26)$ & $\mathrm{n} / \mathrm{a}$ & $\mathrm{n} / \mathrm{a}$ \\
\hline$p$-value & $<0.0001$ & 0.0253 & $\mathrm{n} / \mathrm{a}$ & $\mathrm{n} / \mathrm{a}$ \\
\hline
\end{tabular}

${ }^{\mathrm{a}}$ Missing data were excluded; number of patients does not add up to $100 \% ; n / a$, not applicable 


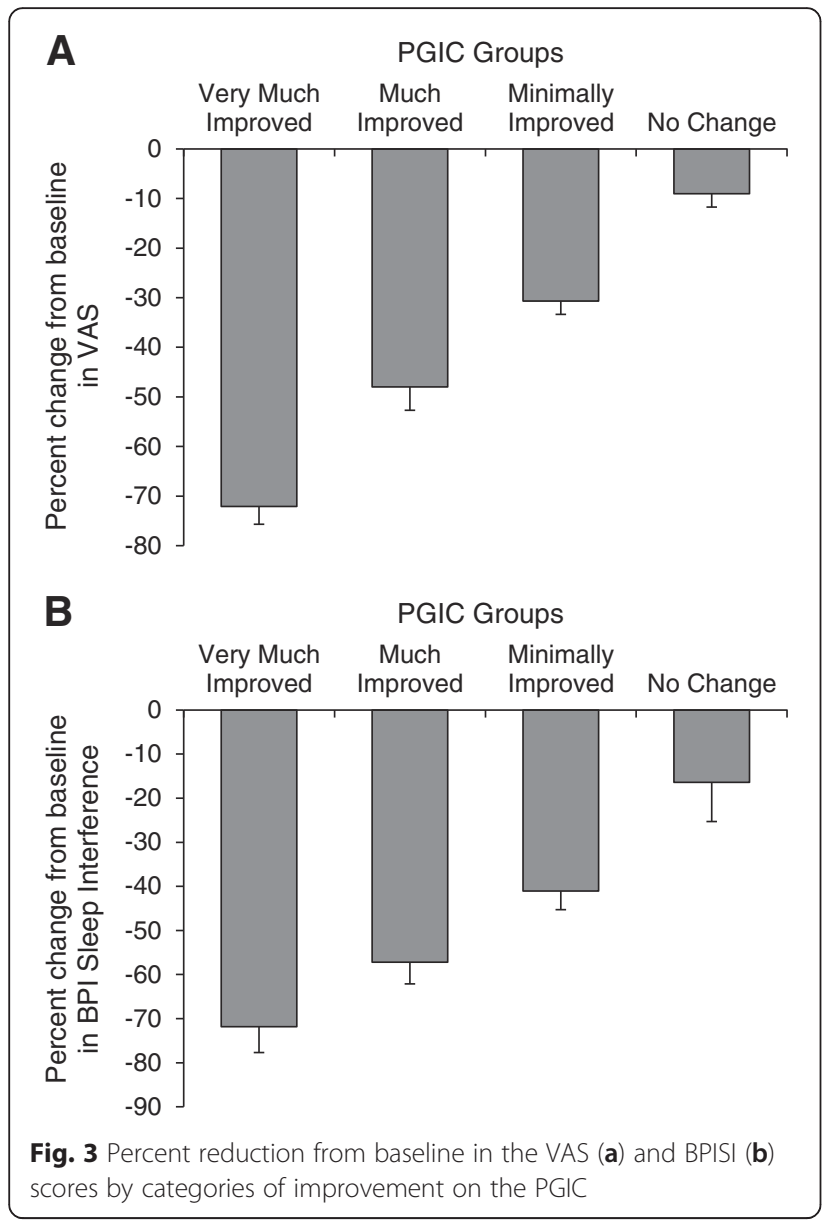

both significant predictive factors for being "Much" or "Very Much" improved on the PGIC (Table 6). However, compared with the BPISI, the percent change in VAS had a larger regression coefficient (0.03 vs. 0.006) and was of greater significance $(p<0.0001$ vs. $p=0.0082)$. Because adding the interaction between percent changes in the VAS and BPISI scores to the regression model showed no significance $(p=0.4808)$ for being "Much" or "Very Much" improved on the PGIC (Table 6), these variables acted as independent predictive factors for overall improvement.

\section{Discussion}

The intensity of neuropathic pain tends to progress throughout the day, being worst at night and significantly impairing sleep $[6,7,27]$. Inadequate or poorquality sleep may in turn contribute to stress and other negative consequences of living with pain, including reduced pain tolerance $[6,8,10,13]$. In this analysis, we investigated the correlation between G-GR-mediated changes in BPISI, VAS pain scores, and PGIC scores at the individual patient level.

In a prior analysis, positive correlations were observed among VAS, overall BPI scores, pain interference on the $\mathrm{BPI}$, and PGIC, suggesting positive feedback loops in which pain interferes with patient functioning, and poor functioning enhances pain [20]. Here we have extended the analysis to evaluate the relationship with pain-associated sleep interference. As in our prior analysis, a $30 \%$ reduction in pain intensity was chosen as a cut-point for evaluating correlations. In accordance with IMMPACT recommendations for determining clinically important differences in pain intensity reductions $\geq 30 \%$ are considered "moderately important" improvements, whereas decreases of $\geq 50 \%$ are considered "substantial" improvements [26, 28]. Use of the $30 \%$ cutoff was considered a conservative approach.

Not surprisingly, clear correlations were observed in our analysis among pain reduction, pain-associated sleep interference and PGIC. Consistent with the notion that mechanisms underlying pain relief and sleep improvement may be distinct, both VAS and BPISI were independent predictors for patients' reporting "Much" or "Very Much" improvement on the PGIC. In addition, $39.5 \%$ of PHN patients with no clinically significant reduction in VAS still had a clinically significant reduction in BPISI. As gabapentin is known to improve sleep quality by increasing slowwave sleep in both normal adults (31) and in patients with epilepsy (32), a direct effect on sleep may have contributed to improvements in BPISI independent of pain reduction.

No correlations were observed between BPISI and VAS for those with a $\leq 30 \%$ change. This result may not be surprising, since $a<30 \%$ change in VAS is considered minimally important; it is likely that any correlations, should they exist, are lost due to the very low signal.

Table 4 Relationship between percent reduction from baseline in VAS and improvement on the PGIC

\begin{tabular}{|c|c|c|c|c|}
\hline & $\begin{array}{l}\geq 30 \% \text { reduction in VAS } \\
(n=285)\end{array}$ & $\begin{array}{l}<30 \% \text { reduction in VAS } \\
(n=240)\end{array}$ & $\begin{array}{l}\text { Difference } \\
\%(95 \% \mathrm{Cl})\end{array}$ & $p$-value \\
\hline "Much" or "Very Much" improved on PGIC, n (\%) & $200(70.2)$ & $43(17.9)$ & $52.26(45.06,59.45)$ & $<0.0001$ \\
\hline Not improved on $\mathrm{PGIC}^{\mathrm{a}}, \mathrm{n}(\%)$ & $85(29.8)$ & $197(82.1)$ & $-52.26(-59.45,-45.06)$ & $<0.0001$ \\
\hline Difference, \% (95 \% Cl) & $40.35(32.84,47.86)$ & $-64.17(-71.03,-57.31)$ & $\mathrm{n} / \mathrm{a}$ & $\mathrm{n} / \mathrm{a}$ \\
\hline$p$-value & $<0.0001$ & $<0.0001$ & $\mathrm{n} / \mathrm{a}$ & $\mathrm{n} / \mathrm{a}$ \\
\hline
\end{tabular}

${ }^{a}$ Includes patients from other PGIC categories: Minimally Improved, No Change, Minimally Worse, Much Worse, Very Much Worse; $n / a$, not applicable 
Table 5 Relationship between percent reduction from baseline in BPI Sleep Interference by Pain and improvement on the PGIC

\begin{tabular}{|c|c|c|c|c|}
\hline & $\geq 30 \%$ reduction in BPI Sleep Interference & $<30 \%$ reduction in BPI Sleep Interference & Difference & $p$-value \\
\hline & $(n=301)$ & $(n=171)$ & $\%(95 \% \mathrm{Cl})$ & \\
\hline $\begin{array}{l}\text { "Much" or "Very Much" improved } \\
\text { on PGIC, n (\%) }\end{array}$ & $174(57.8)$ & $46(26.9)$ & $30.91(22.23,39.58)$ & $<0.0001$ \\
\hline Not improved on $\mathrm{PGIC}, n$ (\%) & $127(42.2)$ & $125(73.1)$ & $-30.91(-39.58,-22.23)$ & $<0.0001$ \\
\hline Difference, \% (95 \% Cl) & $15.61(7.72,23.50)$ & $-46.29(-55.60,-36.80)$ & $\mathrm{n} / \mathrm{a}$ & $\mathrm{n} / \mathrm{a}$ \\
\hline$p$-value & 0.0001 & $<0.0001$ & $\mathrm{n} / \mathrm{a}$ & $\mathrm{n} / \mathrm{a}$ \\
\hline
\end{tabular}

Includes patients from other PGIC categories: Minimally Improved, No Change, Minimally Worse, Much Worse, Very Much Worse; $n / a$, not applicable

It is important to note that approximately $22 \%$ of patients did not report clinically significant reductions in pain or BPISI but still reported feeling "Much" or "Very Much" improved on the PGIC at the end of treatment. These results suggest a complex relationship among patient-reported outcomes and that changes in other efficacy measures, such as mood, opioid usage, and return to work may also play a role. An analysis of pain reduction, pain interference with sleep, and PGIC in patients treated with placebo may also be of interest. In this study, since the phase 4 study was a real-world, open label study with no placebo control group, a rigorous analysis was not possible.
Our results are consistent with a study of pregabalin in patients with diabetic peripheral neuropathy (DPN) or PHN that showed similar correlations between pain relief, sleep improvement, and improvements in quality of life, and these improvements were not solely mediated via control of pain or sleep disturbance [14]. Interestingly, a different pregabalin study in patients with neuropathic pain of any origin reported that improvement in sleep was a better predictor than a reduction in pain intensity of improvements in health-related quality of life [29].

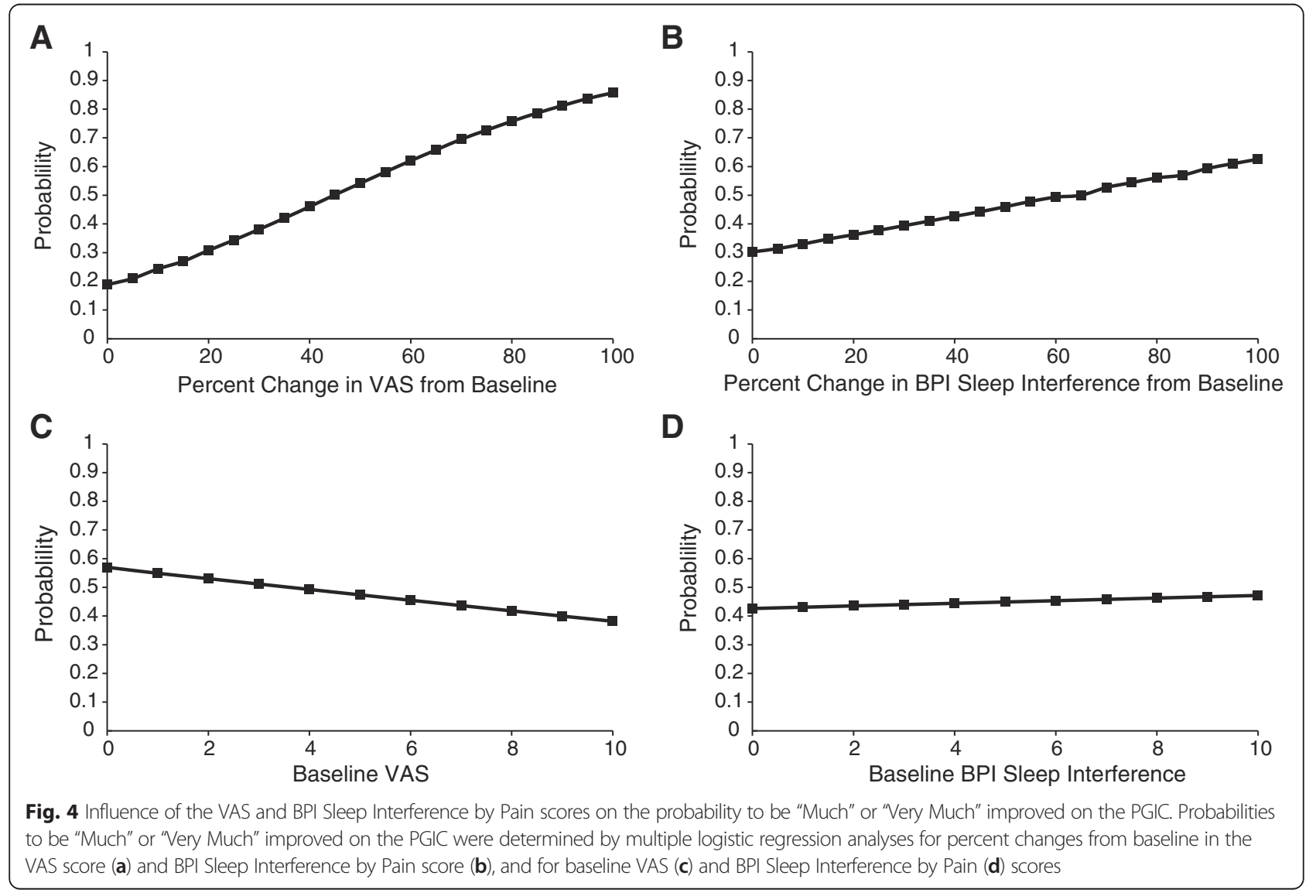


Table 6 Comparison between percent changes in VAS and BPI Sleep Interference by Pain as predictive factors for being "Much" or "Very Much" improved on the PGIC

\begin{tabular}{llll}
\hline Dependent variable & Predictive factors & $\begin{array}{l}\text { Regression } \\
\text { coefficient }\end{array}$ & p-value \\
\hline $\begin{array}{l}\text { "Much" and "Very Much" } \\
\text { improved on the PGIC }\end{array}$ & $\begin{array}{l}\text { Percent change } \\
\text { in VAS }\end{array}$ & 0.02988 & $<0.0001$ \\
& $\begin{array}{l}\text { Percent change in } \\
\text { BPI Sleep Interference }\end{array}$ & 0.00616 & 0.0082 \\
& $\begin{array}{l}\text { Interaction between } \\
\text { percent changes } \\
\text { in VAS and BPI } \\
\text { Sleep Interference }\end{array}$ & & \\
& 0.00005 & 0.4808 \\
\end{tabular}

\section{Conclusions}

For the majority of patients with PHN and treated with G-GR in these clinical trials, clinically significant reductions in pain intensity and pain-associated sleep interference were correlated with, and independently predicted, feeling "Much" or "Very Much" improved at the end of the G-GR treatment. For optimal patient care, clinicians should consider reducing the impact of pain on quality of sleep as well as overall pain reduction.

\section{Competing interests}

SB and IB are former employees of Depomed. The authors declare that they have no competing interests.

\section{Authors' contributions}

NM led the design and conception of the study, reviewed and edited the manuscript, and contributed to data analysis. RS contributed to the design and conception of the study, reviewed and edited the manuscript. IB oversaw statistical analyses and drafted the manuscript. SB and AG contributed to the design and conception of the study, and reviewed and edited the manuscript. All authors read and approved the final manuscript.

\section{Disclosure}

This study was funded by Depomed, Inc. IB and SB are former employees and shareholders of Depomed, Inc. NM is a speaker for Depomed, Inc. No funding was received by Weill Cornell or Memorial Sloan Kettering for this project.

\section{Author details}

'Weill Cornell Medical College of Cornell University, New York, NY, USA.

${ }^{2}$ Depomed, Inc., Newark, CA, USA. ${ }^{3}$ St. Francis Hospital, Roslyn, NY, USA.

${ }^{4}$ Memorial Sloan Kettering Cancer Center, New York, NY, USA.

Received: 1 June 2015 Accepted: 24 March 2016

Published online: 01 April 2016

\section{References}

1. Gharibo C, Kim C. Neuropathic pain of postherpetic neuralgia. Pain Med News. 2011;9:84-92.

2. Pickering $G$, Leplege $A$. Herpes zoster pain, postherpetic neuralgia, and quality of life in the elderly. Pain Pract. 2011;11:397-402.

3. Lukas K, Edte A, Bertrand I. The impact of herpes zoster and post-herpetic neuralgia on quality of life: patient-reported outcomes in six European countries. Z Gesundh Wiss. 2012;20:441-51.

4. Jensen MP, Chodroff MJ, Dworkin RH. The impact of neuropathic pain on healthrelated quality of life: review and implications. Neurology. 2007;68:1178-82.

5. Drolet M, Brisson M, Schmader KE, Levin MJ, Johnson R, Oxman MN, et al. The impact of herpes zoster and postherpetic neuralgia on health-related quality of life: a prospective study. CMAJ. 2010;182:1731-6.

6. Roehrs T, Roth T. Sleep and pain: interaction of two vital functions. Semin Neurol. 2005;25:106-16.
7. Odrcich M, Bailey JM, Cahill CM, Gilron I. Chronobiological characteristics of painful diabetic neuropathy and postherpetic neuralgia: diurnal pain variation and effects of analgesic therapy. Pain. 2006;120:207-12.

8. Lautenbacher S, Kundermann B, Krieg JC. Sleep deprivation and pain perception. Sleep Med Rev. 2006;10:357-69.

9. Gore M, Brandenburg NA, Dukes E, Hoffman DL, Tai KS, Stacey B. Pain severity in diabetic peripheral neuropathy is associated with patient functioning, symptom levels of anxiety and depression, and sleep. J Pain Symptom Manage. 2005;30:374-85

10. Argoff CE. The coexistence of neuropathic pain, sleep, and psychiatric disorders: a novel treatment approach. Clin J Pain. 2007;23:15-22.

11. Roehrs TA, Harris E, Randall S, Roth T. Pain sensitivity and recovery from mild chronic sleep loss. Sleep. 2012;35:1667-72.

12. Chhangani BS, Roehrs TA, Harris EJ, Hyde M, Drake C, Hudgel DW, et al. Pain sensitivity in sleepy pain-free normals. Sleep. 2009;32:1011-7.

13. Smith MT, Haythornthwaite JA. How do sleep disturbance and chronic pain inter-relate? Insights from the longitudinal and cognitive-behavioral clinical trials literature. Sleep Med Rev. 2004;8:119-32.

14. Vinik A, Emir B, Cheung R, Whalen E. Relationship between pain relief and improvements in patient function/quality of life in patients with painful diabetic peripheral neuropathy or postherpetic neuralgia treated with pregabalin. Clin Ther. 2013;35:612-23.

15. Rauck RL, Irving GA, Wallace MS, Vanhove GF, Sweeney M. Once-daily gastroretentive gabapentin for postherpetic neuralgia: integrated efficacy, time to onset of pain relief and safety analyses of data from two phase 3, multicenter, randomized, double-blind, placebo-controlled studies. J Pain Symptom Manage. 2013;46:219-28.

16. Gupta A, Li S. Safety and efficacy of once-daily gastroretentive gabapentin in patients with postherpetic neuralgia aged 75 years and over. Drugs Aging. 2013;30:999-1008.

17. Backonja MM, Canafax DM, Cundy KC. Efficacy of gabapentin enacarbil vs placebo in patients with postherpetic neuralgia and a pharmacokinetic comparison with oral gabapentin. Pain Med. 2011;12:1098-108.

18. Rowbotham M, Harden N, Stacey B, Bernstein P, Magnus-Miller L. Gabapentin for the treatment of postherpetic neuralgia: a randomized controlled trial. JAMA. 1998;280:1837-42.

19. Rice ASC, Maton S, Group PNS. Gabapentin in posterpetic neuralgia: a randomised, double blind, placebo controlled study. Pain. 2001;94:215-24.

20. Kantor D, Panchal S, Patel V, Bucior I, Rauck R. Treatment of postherpetic neuralgia with gastroretentive gabapentin: interaction of patient demographics, disease characteristics, and efficacy outcomes. J Pain. 2015;16:1300-11.

21. Wallace MS, Irving G, Cowles VE. Gabapentin extended-release tablets for the treatment of patients with postherpetic neuralgia: a randomized, double-blind, placebo-controlled, multicentre study. Clin Drug Investig. 2010;30:765-76.

22. Sang CN, Sathyanarayana R, Sweeney M, Investigators DMS. Gastroretentive gabapentin (G-GR) formulation reduces intensity of pain associated with postherpetic neuralgia (PHN). Clin J Pain. 2013;29:281-8.

23. Markley HG, Dunteman ED, Kareht S, Sweeney M. Real-world experience with once-daily gabapentin for the treatment of postherpetic neuralgia (PHN). Clin J Pain. 2015;31:58-65.

24. Farrar JD, Young JPJ, LaMoreaux L, Werth $J$, Poole RM. Clinical importance of changes in chronic pain intensity measured on an 11-point numerical pain rating scale. Pain. 2001;94:149-58.

25. Ostelo RW, Deyo RA, Stratford P, Waddell G, Croft P, Von Korff M, et al. Interpreting change scores for pain and functional status in low back pain: towards international consensus regarding minimal important change. Spine. 2008;33:90-4.

26. Dworkin RH, Turk DC, Wyrwich KW, Beaton D, Cleeland CS, Farrar JT, et al. Interpreting the clinical importance of treatment outcomes in chronic pain clinical trials: IMMPACT recommendations. J Pain. 2008:9:105-21.

27. Belgrade MJ. Following the clues to neuropathic pain. Distribution and other leads reveal the cause and the treatment approach. Postgrad Med. 1999;106:127-32. 35-40.

28. Dworkin RH, Turk DC, McDermott MP, Peirce-Sandner S, Burke LB, Cowan P, et al. Interpreting the clinical importance of group differences in chronic pain clinical trials: IMMPACT recommendations. Pain. 2009;146:238-44.

29. Perez-Lloret S, Rojas GM, Menoni MC, Ruiz G, Velasquez C, Rodriguez H, et al. Pregabalin beneficial effects on sleep quality or health-related quality of life are poorly correlated with reduction on pain intensity after an 8-week treatment course. Clin Neuropharmacol. 2012;35:21-4. 